\title{
Life Skills in a Minute: Sewing on a Button ${ }^{1}$
}

\author{
Heather Janney ${ }^{2}$
}

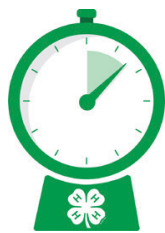

Knowing how to sew on a button comes in handy when you are trying to put on a shirt and suddenly, a button comes loose! Losing a button can make you late, aggravate you, or require that you change clothes. Even though sewing a button back on is quite a simple task, many people refuse to try simply because it seems too hard. They throw away or donate the clothes, buttons missing and all. This publication will help you understand the difference in button types and share methods of sewing a button on.

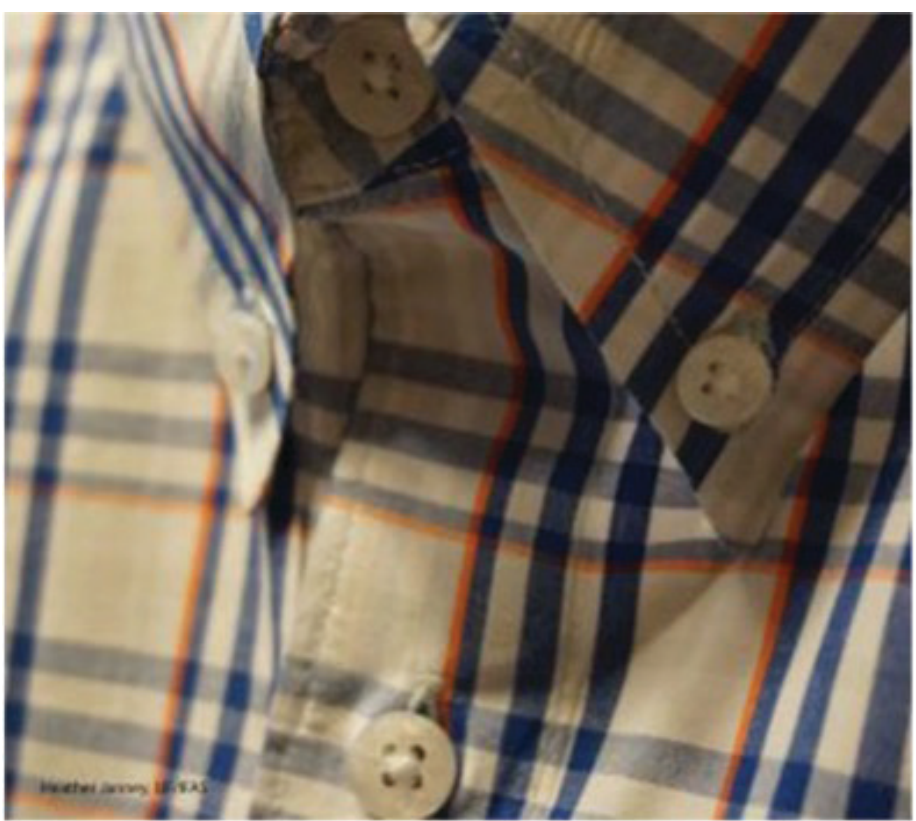

Figure 1. Buttons are included on many garments regardless of the trends or current styles.

Credits: Heather Janney, UF/IFAS
You almost always have extra buttons hidden when you buy a garment. They might be sewn on to a tag inside the shirt or even in a plastic bag alongside the price tag.

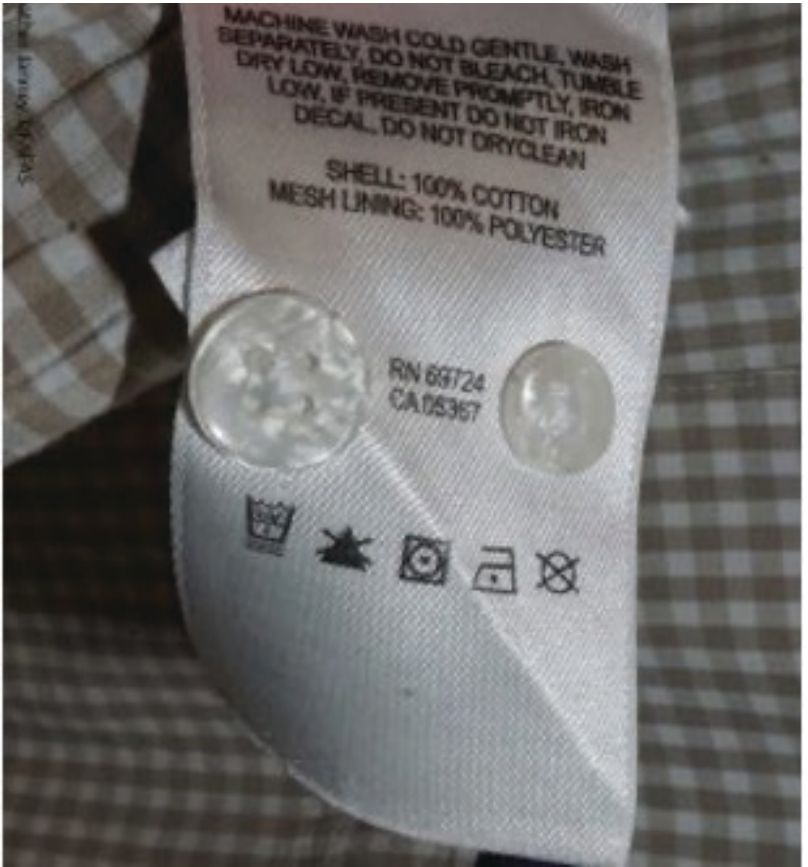

Figure 2. Extra buttons for a garment may be found sewn onto a tag within the garment.

Credits: Heather Janney, UF/IFAS

\section{Two Main Types of Buttons: Flat and Shank}

The choice of button depends on the use of the garment and the purpose of the button on the garment. Heavier fabric requires the use of heavier and larger buttons; lighter fabric

1. This document is $4 \mathrm{H} 414$, one of a series of the 4-H Youth Development Department, UF/IFAS Extension. Original publication date August 2021. Visit the EDIS website at https://edis.ifas.ufl.edu for the currently supported version of this publication.

2. Heather M. Janney, county Extension director and Extension agent II, MS, UF/IFAS Extension Columbia County, Lake City, FL 32055.

The Institute of Food and Agricultural Sciences (IFAS) is an Equal Opportunity Institution authorized to provide research, educational information and other services only to individuals and institutions that function with non-discrimination with respect to race, creed, color, religion, age, disability, sex, sexual orientation, marital status,

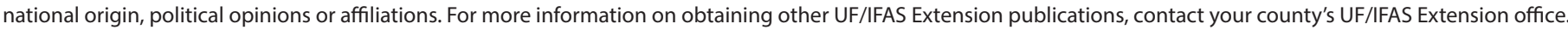
U.S. Department of Agriculture, UF/IFAS Extension Service, University of Florida, IFAS, Florida A \& M University Cooperative Extension Program, and Boards of County Commissioners Cooperating. Nick T. Place, dean for UF/IFAS Extension. 
needs lighter and smaller buttons. Buttons may blend with the fabric of a garment, or they can call attention to an area. It depends on your preference and the purpose of the buttons.

Flat buttons are just that: flat. Some flat buttons have two holes, and some have four. Four-hole buttons are meant for use where they will receive more wear and tear. Meanwhile, two-hole buttons are for applications with a lighter use. As a result, to sew on a four-hole button takes much more thread, which makes the attachment much stronger. These can be sewn by hand or by machine (if you happen to have a sewing machine available to you).

Shank buttons have what is referred to as a shank. A shank is a spacing of either thread or button material that allows spacing for the fabric that will be buttoned together. Hence, the purpose of a button shank is to raise the button above and through the hole so that it sits above the buttonhole. Shank buttons can only be sewn by hand onto garments.

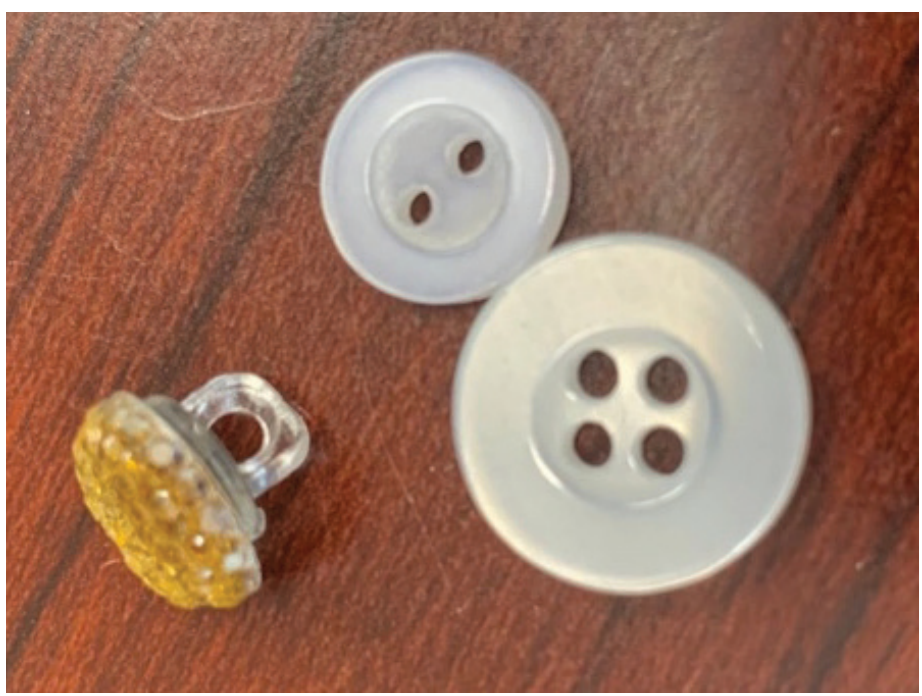

Figure 3. The button on the bottom left is a shank button. The other two are flat buttons, one a two-hole flat button and the other a fourhole flat button.

Credits: Heather Janney, UF/IFAS

\section{Sewing on a Button: Preparation Supplies}

Thread

Needle

Button

Scissors

Optional: needle threader and a thimble
You'll need to prepare your needle. Cut approximately 16 inches of thread, thread it through the eye (hole) of your needle, and pull both thread tails evenly together. Tie a knot at the end of the thread. You could use a single thread, but it is normally not strong enough for button sewing unless you have a thick thread. If you are having trouble getting the thread through the eye of the needle, use a needle threader to help. These small silver devices normally come with a packet of needles and can be useful when it is hard to see to thread a needle.

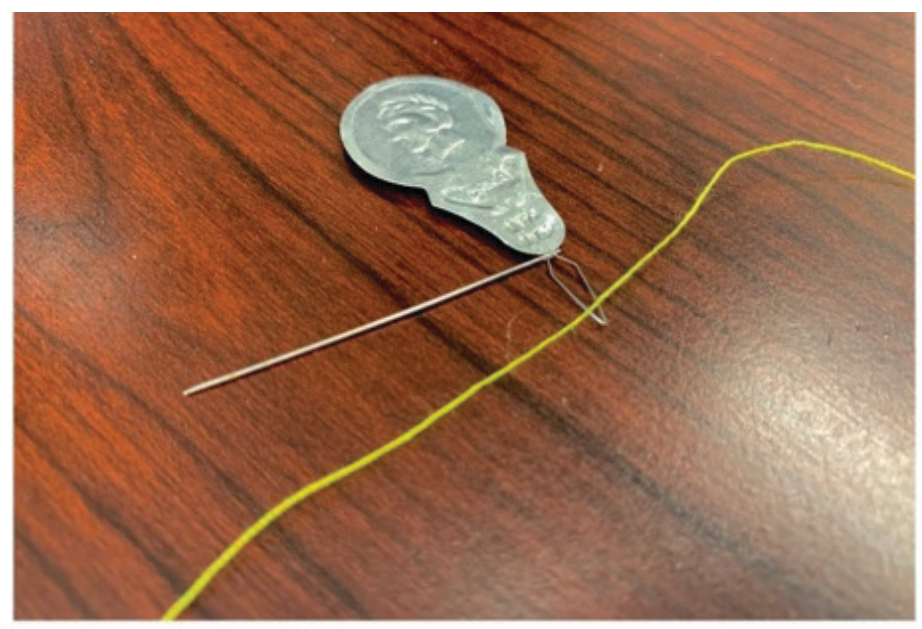

Figure 4. Pictured is a needle threader that has been inserted into the eye of a needle with thread placed through its loop ready to be pulled back for threading the needle.

Credits: Heather Janney, UF/IFAS

\section{How to Hand Sew a Button-Flat Two-Hole}

If you are replacing a button, you should see clearly where to sew it. On the wrong side of the fabric (the inside of your garment), put your needle through the fabric and come up to the right side of the fabric. Thread the needle through one side of the button. Make sure the button is centered on the mark, and put the needle back down through the opposite hole and into the fabric. To create a shank, place a toothpick or a needle under the thread where you are going from hole to hole of the button. Stitch through the holes a few more times. Finally, to finish it off, bring the needle up to the top but not through the buttonhole. Wrap the thread around the stitches a few times tightly. Pass the needle to the inside of the garment and knot it off. 


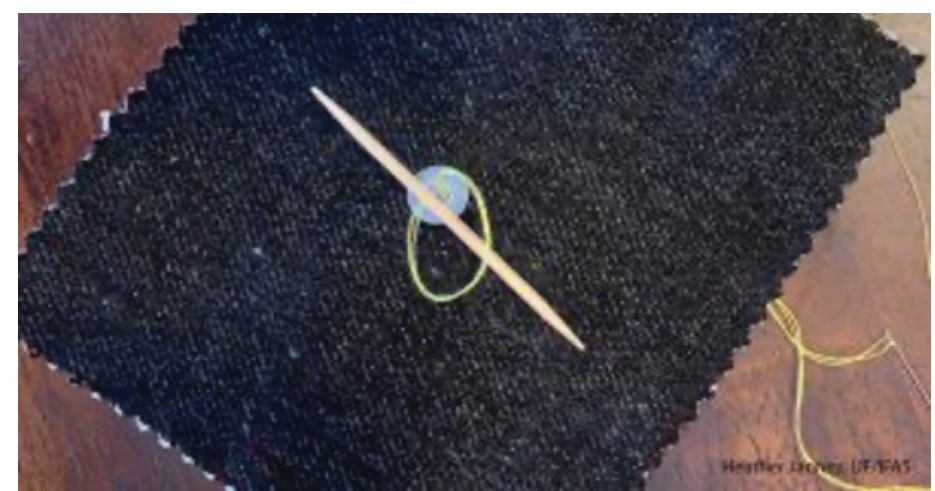

Figure 5. Placing a toothpick atop your button will allow for enough thread to create a shank. This allows for spacing when using a buttonhole.

Credits: Heather Janney, UF/IFAS

\section{How to Hand Sew a Button-Flat Four-Hole}

Similarly, this process requires threading the needle and starting on the backside of the fabric. In contrast, you will thread the needle through one hole of the button, diagonally through another hole of the button, and back to the inside of the fabric. Repeat this going through the opposite set of holes, creating an " $\mathrm{X}$ " on top of the button. Stitch through the holes a few more times in a cross pattern. As a result, most four-hole buttons are sewn with the cross pattern, but you could also sew it going across or down, so you have two bars. This is just a personal preference. If you have a strong thread and enough stitches, it will hold just as well. Don't forget to use a toothpick or needle to create the thread shank for your button. Knot the thread off in the same manner as the two-hole button.

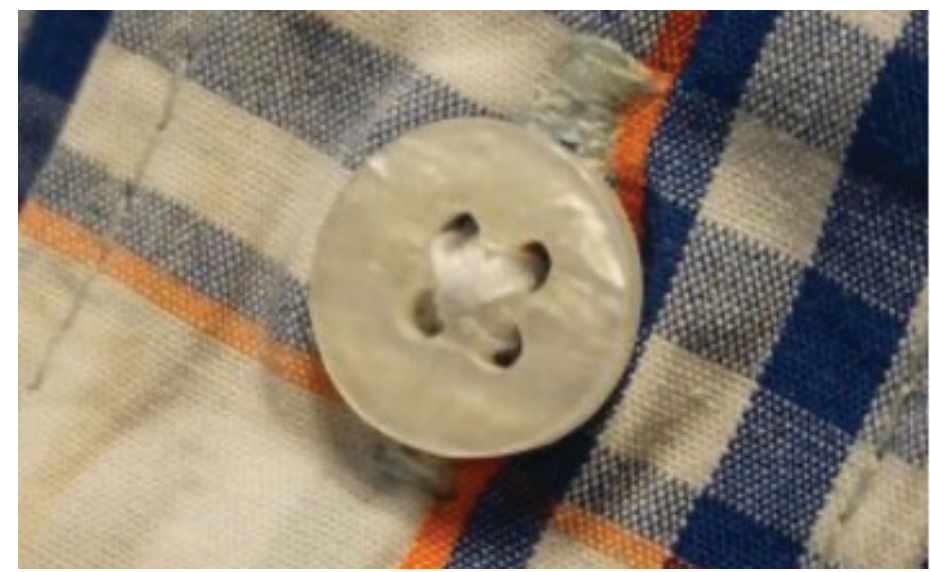

Figure 6. With a flat four-hole button, thread will form an " $x$ " on top of the button.

Credits: Heather Janney, UF/IFAS

\section{How to Sew a Button by Hand with a Shank}

Finally, sewing a button with a shank starts out the same way. However, instead of passing the needle through a buttonhole, you will be passing it through the shank (or hole in the post) underneath. Thread your needle with double thread, and take note of or mark the position of the button. Bring the thread from the underside of the fabric to the top. Place the thread through the button shank and put the needle back down into the fabric. Bring the needle to the top and stitch through the shank a few more times. Bring the needle down to the inside of the fabric and knot it off a couple of times.

Sewing on a button is relatively easy when you have patience. It can be difficult to get the needle through the fabric or even to place the button back where it came from. With practice at this skill, you'll be able to keep all your clothes in working order. And to top it off, you'll be able to quickly fix a missing button in the future. Now it's just time to invest in a sewing kit.

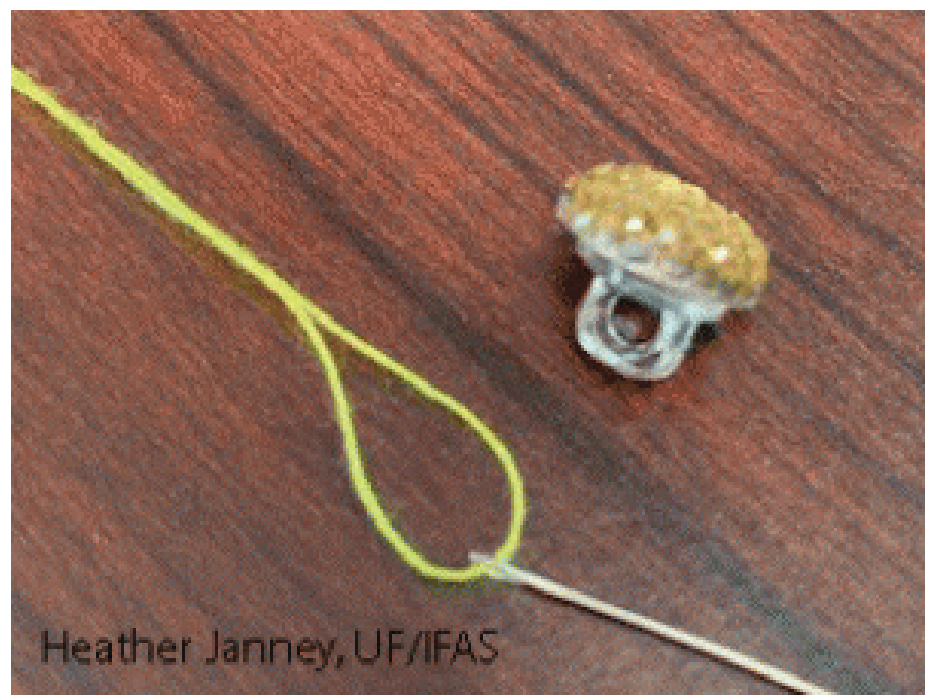

Figure 7. A shank button.

Credits: Heather Janney, UF/IFAS

\section{Sources}

Baker, M. (2006). Buttons \& buttonholes. University of Kentucky Cooperative Extension: CT-MMB.189. Available at https://fcs-hes.ca.uky.edu/sites/fcs-hes.ca.uky.edu/files/ ct-mmb-189.pdf

Bradshaw, S., Thompson, T., Maxfield, L., \& Shirley, L. (2012). Sewing technique: Buttons. Utah State University: FC/Clothing\&Textiles/2012-09pr. Available at https:// digitalcommons.usu.edu/cgi/viewcontent.cgi? article $=2537$ \&context=extension_curall 